\title{
Hydrologic Modeling of a Highly Managed Watershed Using SWAT
}

\author{
MOHAMMAD MATIN SADDIQI ${ }^{1}$ and M. EKREM KARPUZCU ${ }^{1}$ \\ ${ }^{1}$ Istanbul Technical University
}

July 24, 2020

\begin{abstract}
Anthropogenic activities and climate change are the important factors adversely affecting water resources in Kucuk Menderes Watershed. The watershed is shown as a water-stressed watershed due to increasing population and uncontrolled groundwater use. Water resources management within the watershed has become a challenge and to overcome this challenge, modeling studies are necessary. In this study, a hydrologic model for the watershed was established using SWAT (Soil and Water Assessment Tool). The model calibration and sensitivity analysis were performed by SWAT-CUP (SWAT-Calibration Uncertainty Programs) using Sequential Uncertainty Fitting Version-2 (SUFI-2) method. The model was mostly sensitive to CN2 parameter. Soil and groundwater parameters were the parameter categories that the model was mostly sensitive. The performance of the model was evaluated with P- factor, R- factor and objective functions. P- factor values for the calibration were in the range of $42-75$ $\%$ meaning that the monitoring data were matched by the model within this range. According to the objective functions, the model performance was evaluated as good and satisfactory based on gauge stations. As this study is one of the first watershed modeling studies for the watershed, it will contribute to different studies to be done in water resources management. The results of this study could serve as a basis for a wide range of studies in the watershed such as water budget determination and sectoral water allocation, impact of climate change, future water quality modeling studies and understanding the impact of best management practices applications to prevent further deterioration in water quantity and quality within the watershed.
\end{abstract}

Hydrologic Modeling of a Highly Managed Watershed Using SWAT

1* $^{*}$ Mohammad Matin Saddiqi, ${ }^{1}$ M. Ekrem Karpuzcu

${ }^{1}$ Environmental Engineering Department, Istanbul Technical University, 34469, Maslak, Istanbul/Turkey.

${ }^{*}$ Corresponding Author: saddiqi@itu.edu.tr

Hosted file

Main Text File.docx available at https://authorea.com/users/345936/articles/472005hydrologic-modeling-of-a-highly-managed-watershed-using-swat 


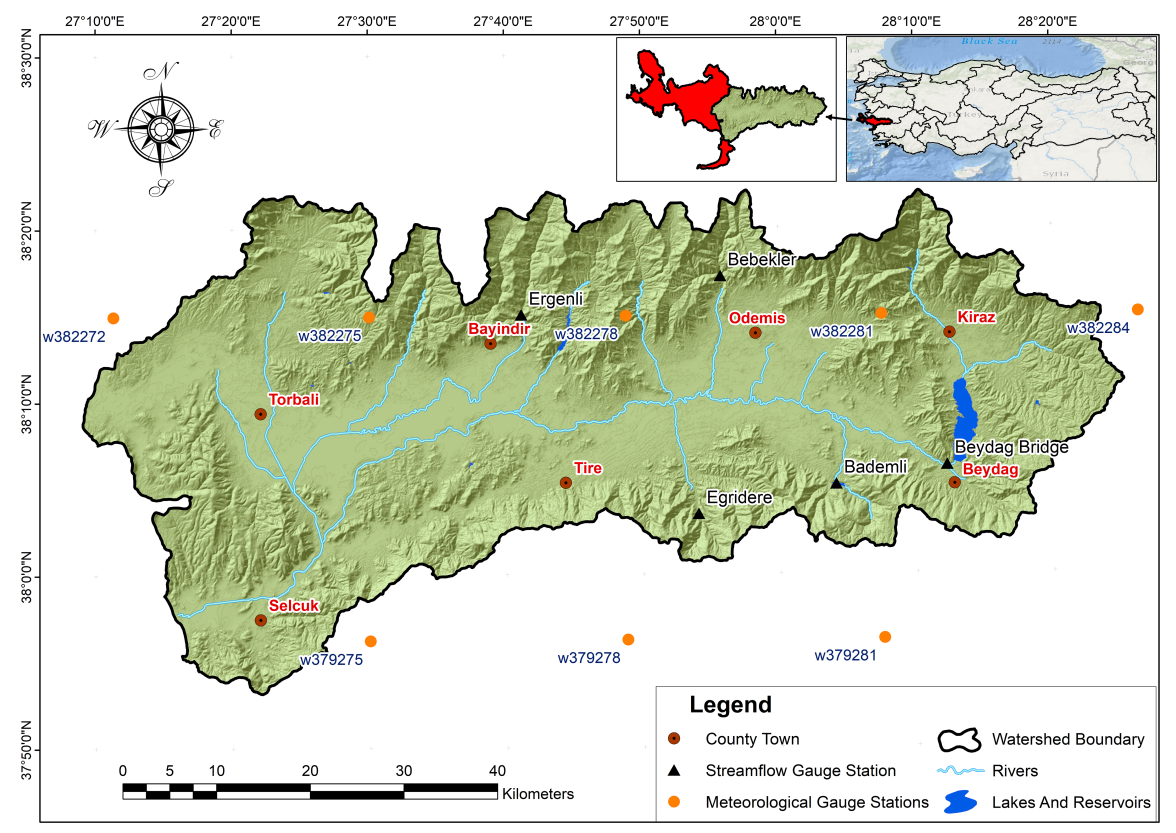



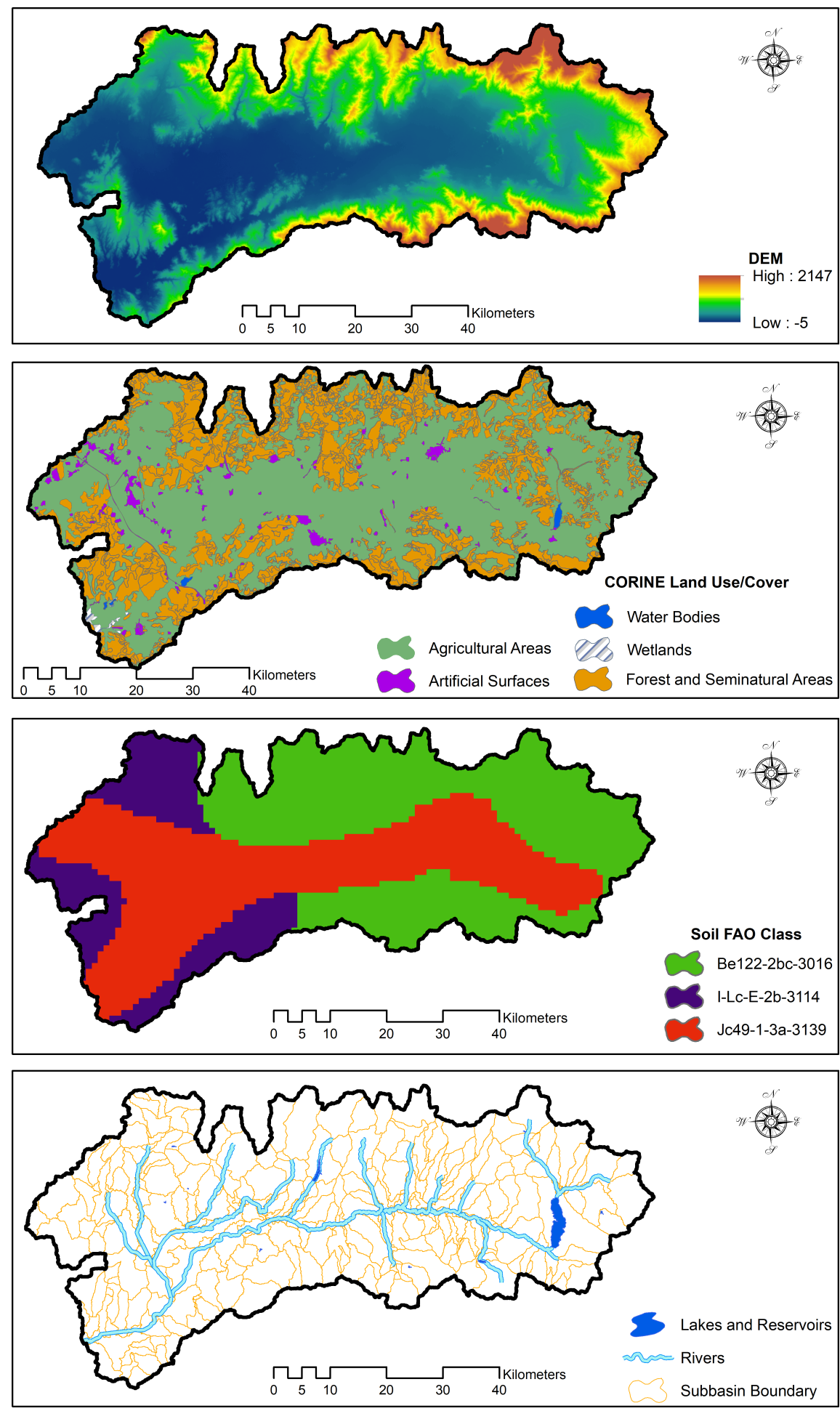

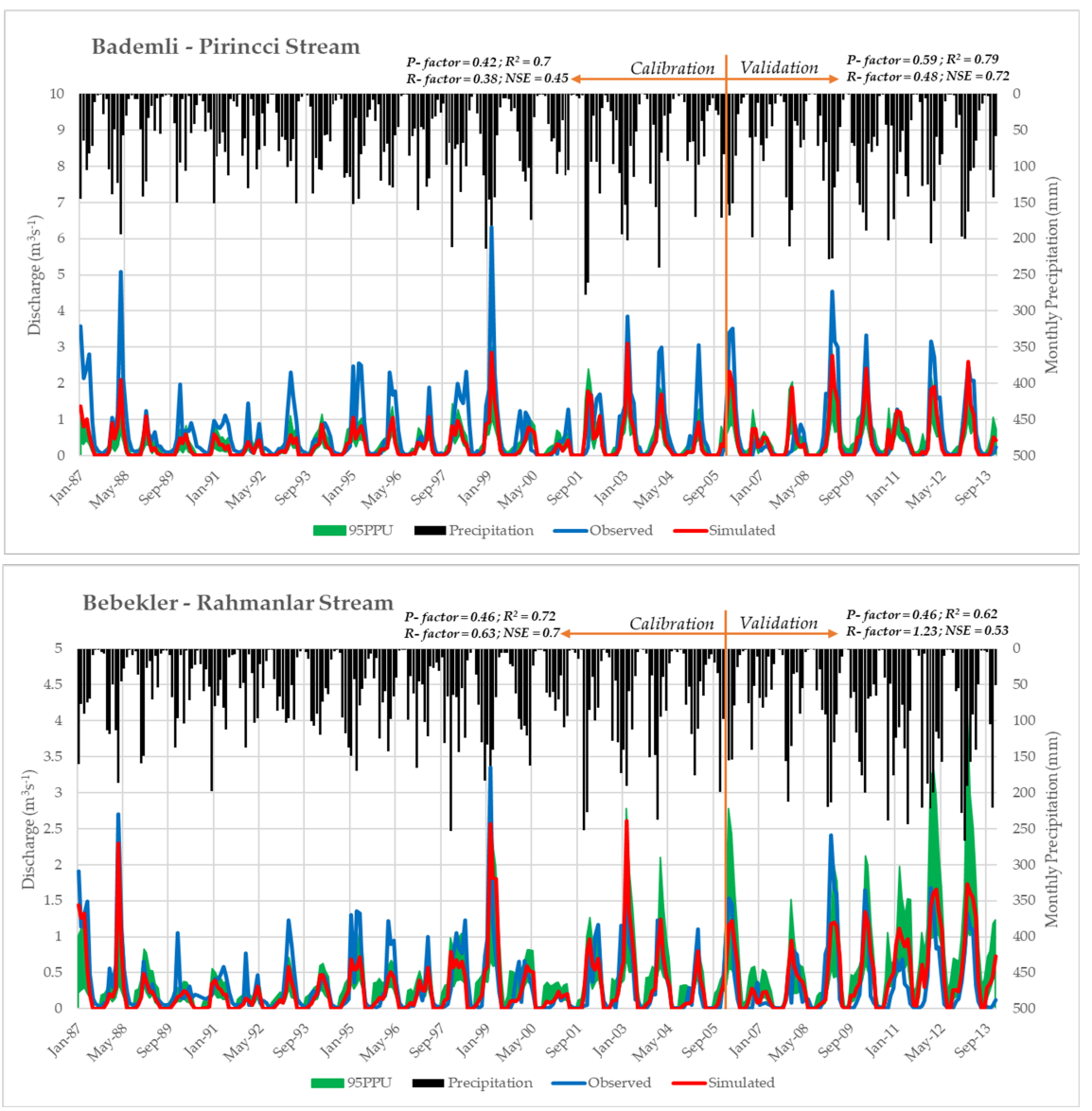

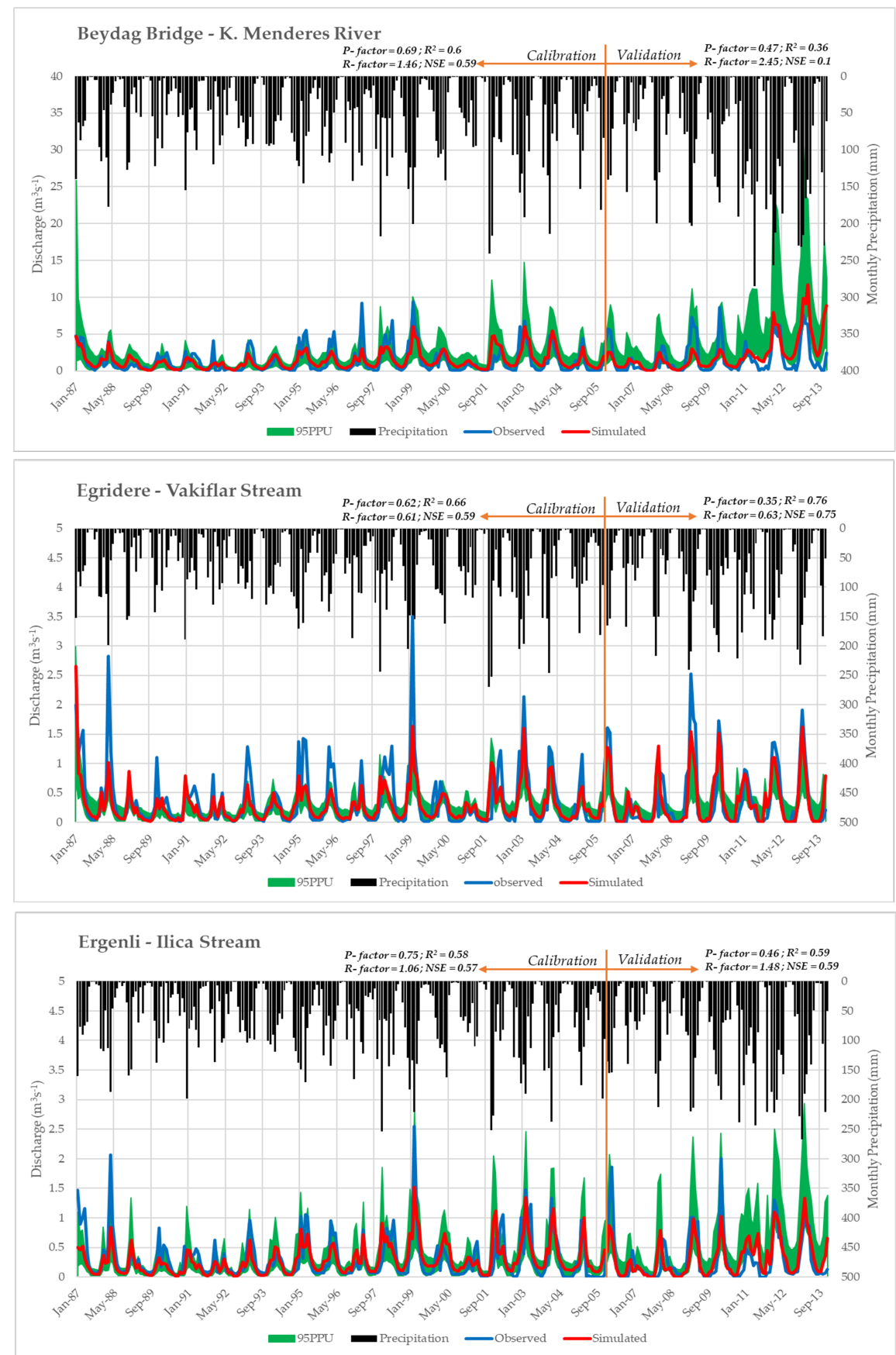